\title{
Crustal structure in the Siwalik Himalayas using magnetotelluric studies
}

\author{
S. G. Gokarn, C. K. Rao, and Gautam Gupta \\ Indian Institute of Geomagnetism, Colaba, Mumbai 400 005, India \\ (Received July 3, 2000; Revised August 8, 2001; Accepted September 27, 2001)
}

\begin{abstract}
Tectonics in the Himalayan foothills is a result of the compressional forces active since the collision between Indian and Eurasian plates and is best understood as a combination of thin skin tectonics and the basement level faulting. In order to delineate the depth extent of various thrusts and faults, wide band Magnetotelluric (MT) studies were conducted at 17 stations over the Una-Mandi profile located in the Lesser Himalayas. These studies indicate that the Palampur thrust may be a composite of two thrust zones which merge together on the south of the MT profile and extends to depths of about $8 \mathrm{~km}$. The Lambagraon syncline flanked by the Sarkaghat anticline on the $\mathrm{NE}$ and the Bahl anticline to the SW, is about $10 \mathrm{~km}$ deep. The crust is underlain by a conductive layer with a resistivity of about $100 \Omega-m$ at depth of about $50 \mathrm{~km}$ below the Palampur thrust and Sarkaghat anticline. This layer is delineated at shallower depths of about $35 \mathrm{~km}$ below the Lambagraon syncline and also on the NE towards the main boundary thrust.
\end{abstract}

\section{Introduction}

Himalaya is a part of an arcuate orogenic belt extending over about $2500 \mathrm{~km}$ on the northern part of the Indian plate, resulting from a collision between the Indian and Eurasian plates. The tectonic setting of the Himalayan mountain belt can best be described in terms of four prominent structural breaks (Mahadevan, 1994) running along the entire length of the Himalayan strike;

1. The main frontal thrust (MFT), also known as the Foothill thrust defines the southern limit of the Himalayan orogeny. This line forms a divide between the Siwalik sediments of the Lesser Himalayas and the Indo-Gangetic alluvials.

2. The main boundary thrust (MBT) regionally separates the Siwalik and other sedimentary sequences of the Lesser Himalayas from the Sub Himalaya and shows moderate to steep northerly dips.

3. The main central thrust (MCT) is essentially a ductile shear zone that separates the crystalline rocks of the Higher Himalaya from the Sub Himalaya and also forms the basal shear of many thrusts.

4. The Indus Tsangpo Suture (ITS) consisting of Ophiolitic melanges and flysch sediments. This is understood to be the line along which the Indian and Eurasian plates are sutured together after the intercontinental collision.

Subsequent to the intercontinental collision, the subduction of the Indian plate is known to have occurred at the ITS. However the seismicity studies (Ni and Barazangi, 1984) indicate that the ITS is essentially an aseismic contact at present. Most of the subsequent subduction seems to be occurring along the MCT and MBT (Gansser, 1964).

Siwaliks are the Late Tertiary sediments deposited be-

Copy right(C) The Society of Geomagnetism and Earth, Planetary and Space Sciences (SGEPSS); The Seismological Society of Japan; The Volcanological Society of Japan; The Geodetic Society of Japan; The Japanese Society for Planetary Sciences. tween the MFT and MBT and are present over almost the entire length of the Himalayan foothills. These sequences have been stratigraphically grouped into the Upper, Middle and Lower Siwaliks by Pilgrim (1913). Many thrusts and fold belts have developed in this region as a result of the post-collision compressional forces, which were subsequently covered by various sedimentary deposits brought down by the rivers and streams in this vast mountain chain (Karunakaran and Ranga Rao, 1976). The post-collision tectonics has resulted in further deformation in the crustal and supra crustal blocks to varying degree of depth extent.

There are very few geophysical studies in this region. Most of the understanding of the thrusts as well as the basement interactions are based on the gravity and seismic studies and deep borehole stratigraphic studies conducted for oil and natural gas prospecting. The rugged terrain in the Siwalik hills makes any systematic studies rather prohibitive. In order to obtain the deep crustal configuration in this region and to delineate the depth extent of the various thrust zones, magnetotelluric (MT) studies were undertaken over an 80 $\mathrm{km}$ long linear profile between Una and Mandi.

\section{Geology and Tectonic Setting of Siwaliks}

Most of the stations are located in the Siwalik sequences deposited during the Lower Pleistocene to Pliocene and the older Dharamsala sequences except for the two stations on the NE of MBT, which are located over the pre-Tertiaries. The geological features are shown in Fig. 1 along with the location of the MT stations. The Upper Siwalik sequences are predominantly conglomerate with minor sandstone and earthy buff and brown claystone whereas, the Middle Siwaliks consist of medium to coarse grained sandstones, pebbly with subordinate claystone and minor conglomerated bands towards the top (Karunakaran and Ranga Rao, 1976). The Lower Siwaliks are alternation of fine to medium grained occasionally pebbly and reddish brown nodular claystone and 


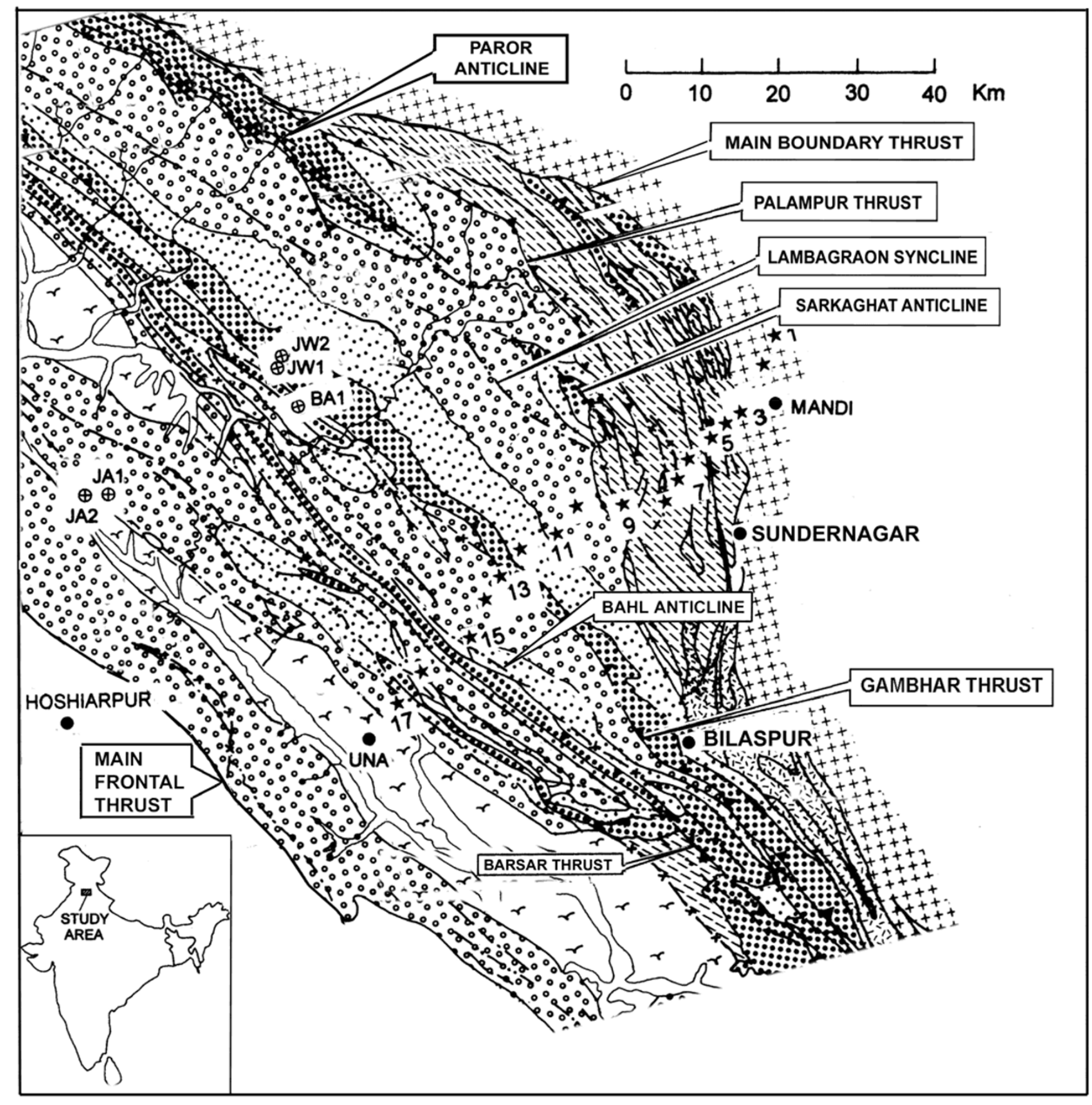

\begin{tabular}{|c|c|c|c|c|c|c|c|}
\hline $\begin{array}{ll}\because & 00 \\
0 & 0 \\
0\end{array}$ & UPPER SIWALIK & $\because \because \because \because$ & MIDDLE SIWALIK & 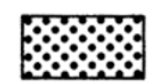 & LOWER SIWALIK & 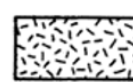 & SUBATHU \\
\hline & PRE-TERTIAF & & DHARAMSALA & \begin{tabular}{|ll}
$r$ & $r$ \\
$r$ & $r$
\end{tabular} & ALLUVIUM & $\star$ & MT STATIONS \\
\hline$\oplus$ & BORE WELLS & $\perp 1$ & THRUST & $-\cdots-$ & SYNCLINES & - $\cdots$ & ANTICLINES \\
\hline
\end{tabular}

Fig. 1. Geological and tectonic map of the survey region (redrawn from Karunakaran and Ranga Rao, 1976) showing the locations of the MT stations. Also shown here are the locations of the deep borewells drilled in the Siwalik region. 


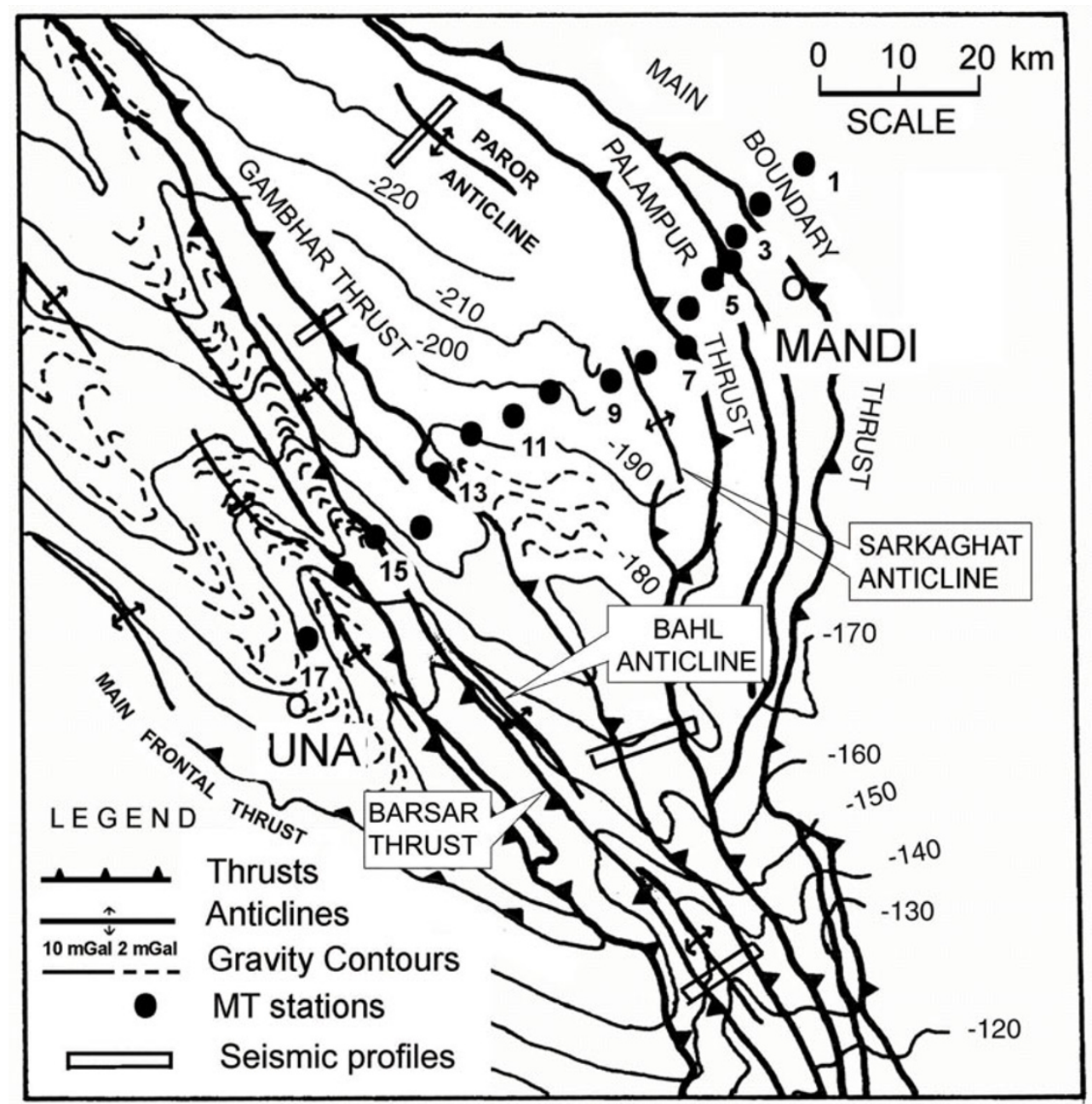

Fig. 2. Bouguer anomaly map of the survey region (redrawn from Raiverman et al., 1994). Also shown are the major tectonic elements, the MT sites and the seismic study profiles.

siltstone (Biswas, 1994). The Upper Siwaliks form the top cover over most part of the profile and the Middle and Lower Siwaliks are delineated over the narrow thrust and anticlinal regions and show a predominantly NW-SE orientation. The Dharamsala and Subathu formations are exposed between the MBT and the Palampur thrust.

The borehole stratigraphic studies discussed later in this section have shown that the Siwalik sequences are underlain by various older sedimentary formations of which the Dharamsala and Subathu are prominent. On the lithological basis, the Dharamsalas are grouped into the Upper and Lower Dharamsala sequences. The Upper Dharamsala comprises of greenish gray fine-grained sandstone whereas, the Lower Dharamsala is predominantly argillaceous with laterally impersistant sandstones (Karunakaran and Ranga Rao, 1976; Biswas, 1994).

In order to determine the prospects of oil and natural gas, numerous borewells have been drilled by the Oil and Natural Gas Corporation Ltd. (erstwhile Oil and Natural Gas Commission) in the anticlinal regions of the Siwalik (Fig. 1). The borewell stratigraphic studies (DST Expert group, 1995) show about 2500-3500 m thick Siwalik sediments. The results of the five borewells are documented between the
MBT and the MFT, of which only the Janauri well (JA2) has reached the basement at depth of $5027 \mathrm{~m}$. At Jwalamukhi well (JW1 and JW2), the basement was not reached even at depths of $6720 \mathrm{~m}$. It is thus inferred that the total thickness of the sedimentary cover is more than $6000 \mathrm{~m}$. All the borewells are drilled over anticlines and thrust zones and thus the average thickness of the sedimentary column may be much greater than the value indicated by the borewell studies.

Bouguer anomaly map shows several short wavelength gravity variations along the NE-SW direction. The gravity variations perpendicular to this direction however are not so prominent. The Bouguer gravity map along with the major tectonic features is shown in Fig. 2. As mentioned earlier, this region has undergone tectonic deformations over extended periods of time and as a consequence, several thrusts and folds have developed in this region, some of which extend deep into the basement. MT survey profile passes from NE, through the MBT, Palampur thrust, Gambhar thrust and the Barsar thrust. Raiverman et al. $(1983,1994)$ have obtained the depth section of the Siwalik region using five seismic profiles, each about 10-15 km long, covering the different tectonic units. Four of the seismic profiles are shown 


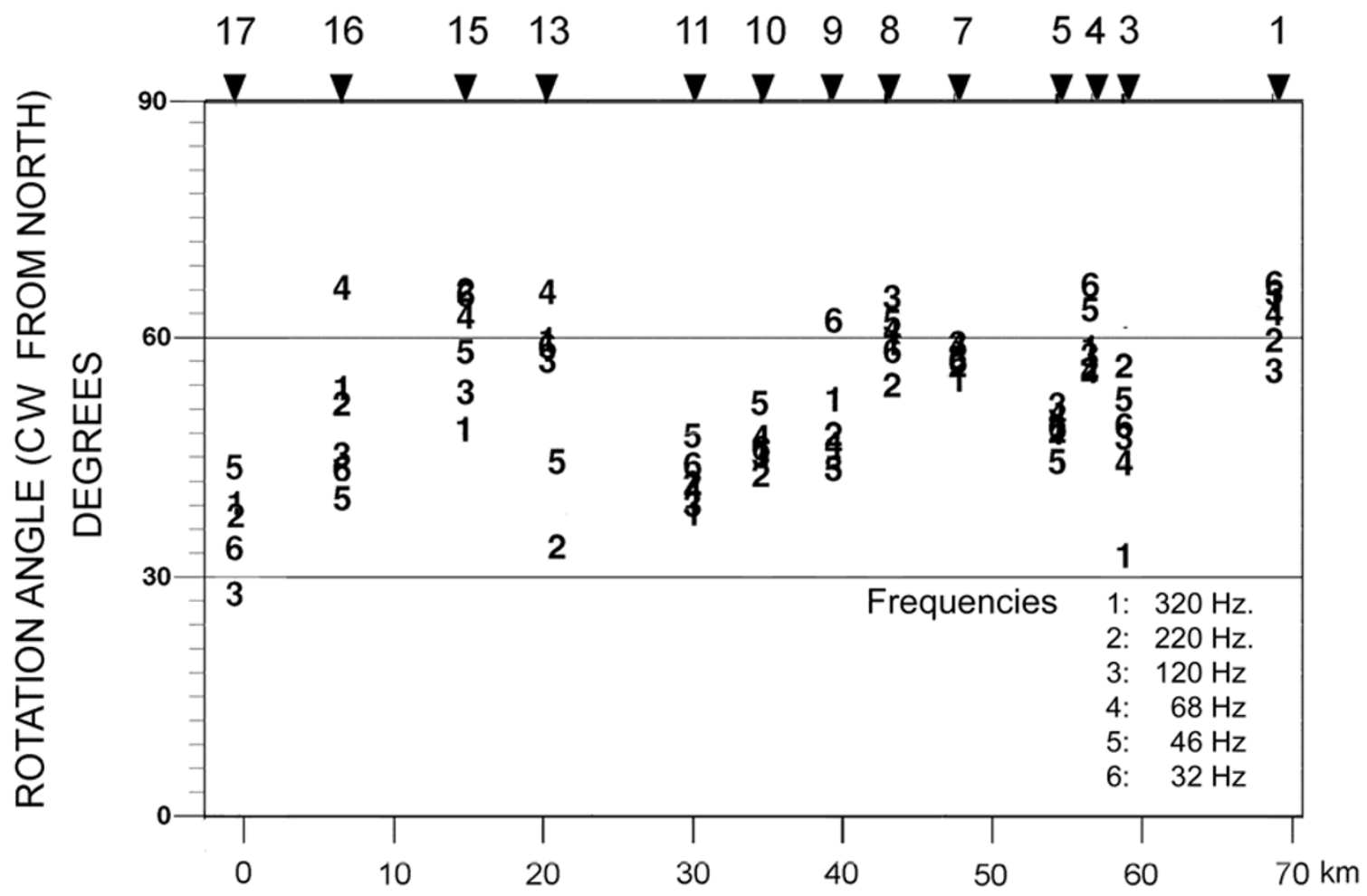

Fig. 3(a). Impedance strike angles obtained by Groom Bailey decomposition at high frequencies.

in Fig. 2 and the fifth is located outside the region covered in this figure. By integrating this data with the gravity and other geological information, they have proposed a strong interplay of the thrusts in the Tertiary cover and the wrench fault system in the pre-Tertiary floor beneath Siwaliks. Thus, both thin skin tectonics and deep basement level tectonic activity may have had substantial contribution to the formation of the sub-surface structure in this region. The tectonic interpretation obtained from these studies is shown in Fig. 8(b) and will be discussed in detail along with the results of the MT studies.

From the Geomagnetic depth sounding (GDS) studies, Reddy and Arora (1993) have reported a high conductivity layer embedded in the crust at depths varying from 10$15 \mathrm{~km}$ below the Himalayan collision region. They have noted that the real induction vectors have maximum length near the MFT and become smaller towards the MBT on the NE and the Indo-Gangetic plains on the SW, indicating a large conductance for this conductive layer below MFT. From the two dimensional modeling studies, these authors have observed that this conductive layer has a resistivity of $1 \Omega-m$ beneath the Indo-Gangetic plains on the south of MFT. Towards the north, it has a higher resistivity of about $100 \Omega-m$. The depth to this layer is about $10 \mathrm{~km}$ on the south of MFT and increases to about $20 \mathrm{~km}$ on the NE towards MCT and the Himalayan collision region.

\section{Data Collection and Analysis Procedure}

MT data were collected at 17 stations over the UnaMandi profile with an inter-station spacing of 5-15 km. Data were collected in the frequency range of $320-0.0005 \mathrm{~Hz}$ using the V-5 MT system procured from M/s Phoenix Geo- physics, Canada. The two horizontal components of the magnetic field variations were measured using the induction coils, whereas the lead chloride electrodes placed about 80-100 $\mathrm{m}$ apart along the magnetic NS and EW directions were used for measuring the electric field. The survey profile is located over the mountainous terrain of the Siwalik range and most of the town developments are in close proximity of the few available roads. Thus the station selection as well as the inter-station spacing were to a large extent governed by the accessibility to the suitable low noise sites. Data were analysed using a single site analysis procedure. A combination of fast Fourier transforms and cascade decimation technique (Wight and Bostick, 1980) was used for obtaining the auto and cross power spectra required for computing the frequency variation of the apparent resistivity and phase of impedance.

\section{Regional Strike Direction}

The response functions (apparent resistivity and phase of impedance) at four stations (2, 6, 12 and 14) were contaminated by cultural noise and hence were not used for further analysis. The impedance tensors at the other 13 stations were decomposed using the tensor decomposition procedure (Groom and Bailey, 1989). The unconstrained decomposition at individual frequencies indicated that the shear had a stable value at most frequencies at all stations. The shear was then constrained to its median value and the decomposition procedure was repeated with unconstrained twist and strike angles. This resulted in a marked improvement in the stability of the twist and the strike angles. The twist was varied in the vicinity of its median value to further decrease the frequency dependence of the observed strike angles. 


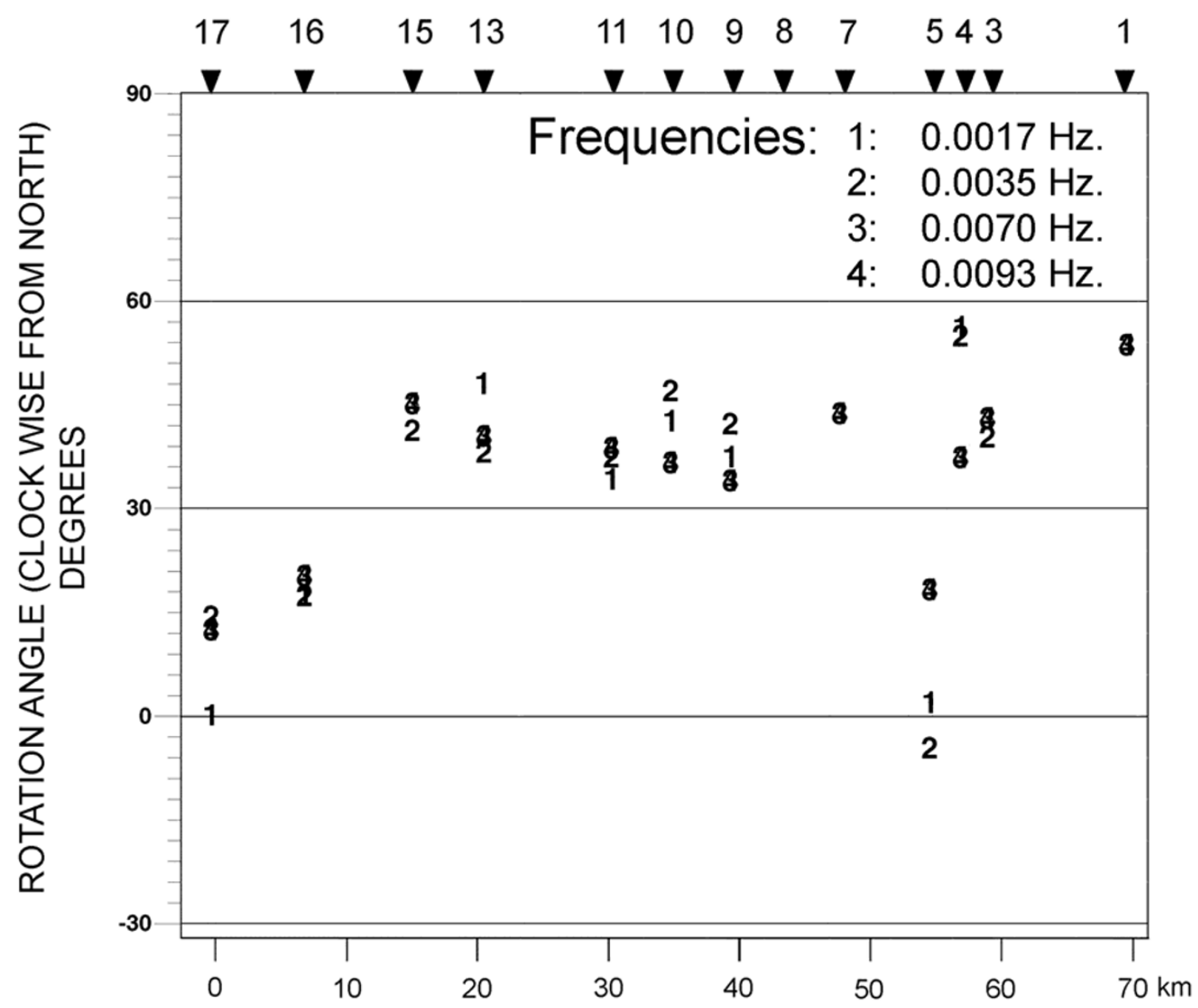

Fig. 3(b). Impedance strike angles obtained by Groom Bailey decomposition at low frequencies.

The strike angles at the high frequency range are shown in Fig. 3(a) and those at low frequencies in the Fig. 3(b). The strike angles at high frequencies are predominantly aligned along the $\mathrm{N} 50^{\circ} \mathrm{E}$ direction whereas, those at low frequencies (Fig. 3(b)) are along $\mathrm{N} 40^{\circ} \mathrm{E}$ at most of the stations. The response functions at the stations 5, 16 and 17 at low frequencies however show different strike angles and thus may need to be checked in detail.

The variations of the apparent resistivities and phases with the Swift rotation angle (Vozoff, 1972) at all frequencies for the station 17 are shown in Fig. 4. The Groom Bailey strike angles, shown as solid squares in this figure have values of about 15 degrees at low frequencies $(<0.1$ $\mathrm{Hz}$ ). It seems that a high conductivity contrast located on the south of the MT profile is influencing the electromagnetic responses at low frequencies at this station. The GDS studies (Reddy and Arora, 1993) have delineated a $10 \mathrm{~km}$ thick conductive layer with resistivity varying between 1 and $100 \Omega-m$ in the deep crust below the Indo-Gangetic plains on the south of MFT, extending northwards below the Himalayan collision region. This layer has a resistivity of about $1 \Omega-m$ on the immediate south of MFT, indicative of a total conductance of $10000 \mathrm{~S}$. The GDS profile is located about $250 \mathrm{~km} \mathrm{SE}$ of the present study region. However the tectonic setting there are similar to those over the
MT profile. The real induction vectors (figure 3 in Reddy and Arora, 1993) show a predominantly NS orientation, implying that the causative body has an EW extension on the south of MFT. The high conductance of this conductive feature seems to influence the low frequency strike angles at the station 17. It may be noted from the Fig. 4 that the strike angles at high frequency $(>0.1 \mathrm{~Hz})$ correspond well with the value of $\mathrm{N} 40^{\circ} \mathrm{E}$ observed at most of the MT stations. Similar behaviour was observed in the MT response at station 16. The ratios of the major and minor resistivities at station 5 were less than a factor of 3.0 throughout the frequency range of the sounding and thus the vertical conductive contrasts in the survey region do not seem to have any significant effects on the electromagnetic responses at this station.

The regional strike direction was assumed to be either along $\mathrm{N} 40^{\circ} \mathrm{E}$ or perpendicular to it. This choice does not affect the response functions at station 5 because of the predominantly one-dimensional nature of the electromagnetic response observed at this station. It is evident from the Fig. 4 that the rotation of the response functions along the regional strike direction of $\mathrm{N} 40^{\circ} \mathrm{E}$ may not differ much from those rotated along the local strike of $\mathrm{N} 15^{\circ} \mathrm{E}$ at the low frequencies. The possible distortions of the geoelectric structure resulting from this deviation will be discussed later, in the section, "Discussions on the deep crust." 
$\begin{array}{ll}\text { Apparent resistivity } & \text { Station: } 17\end{array}$

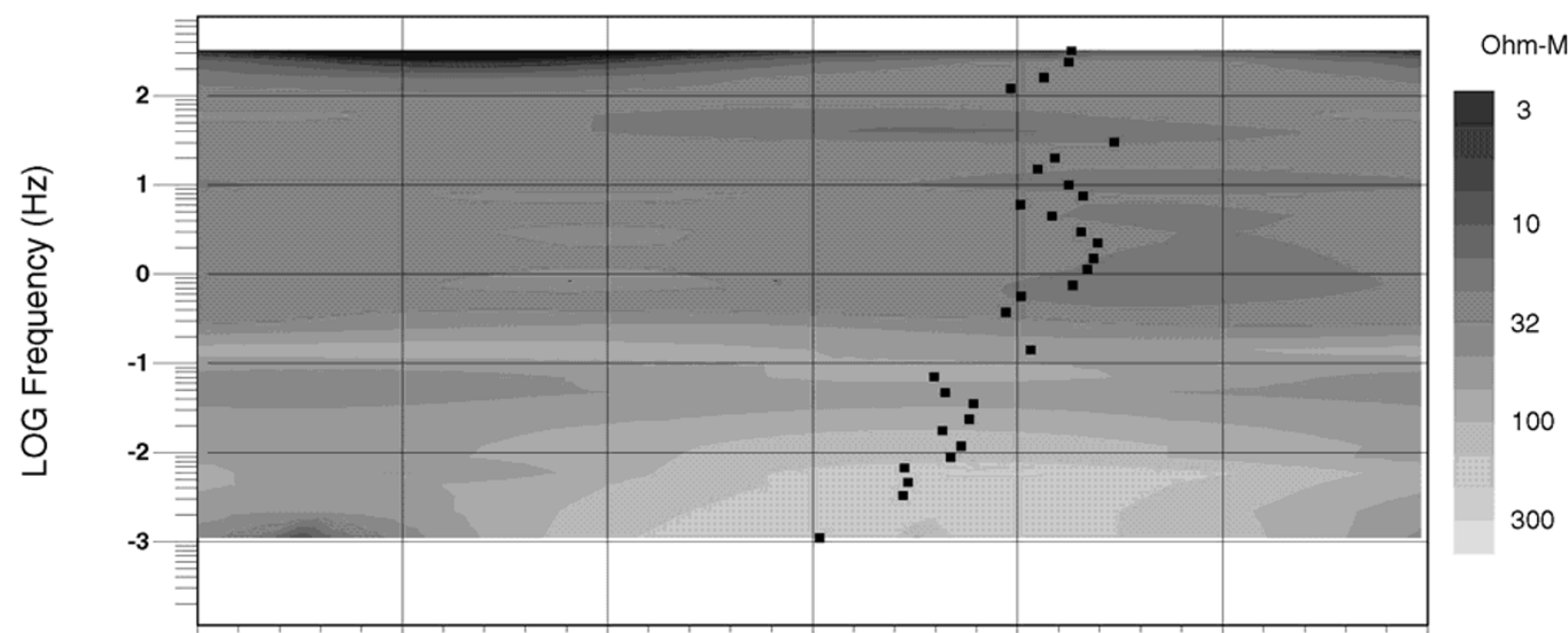

Phase

Station: 17

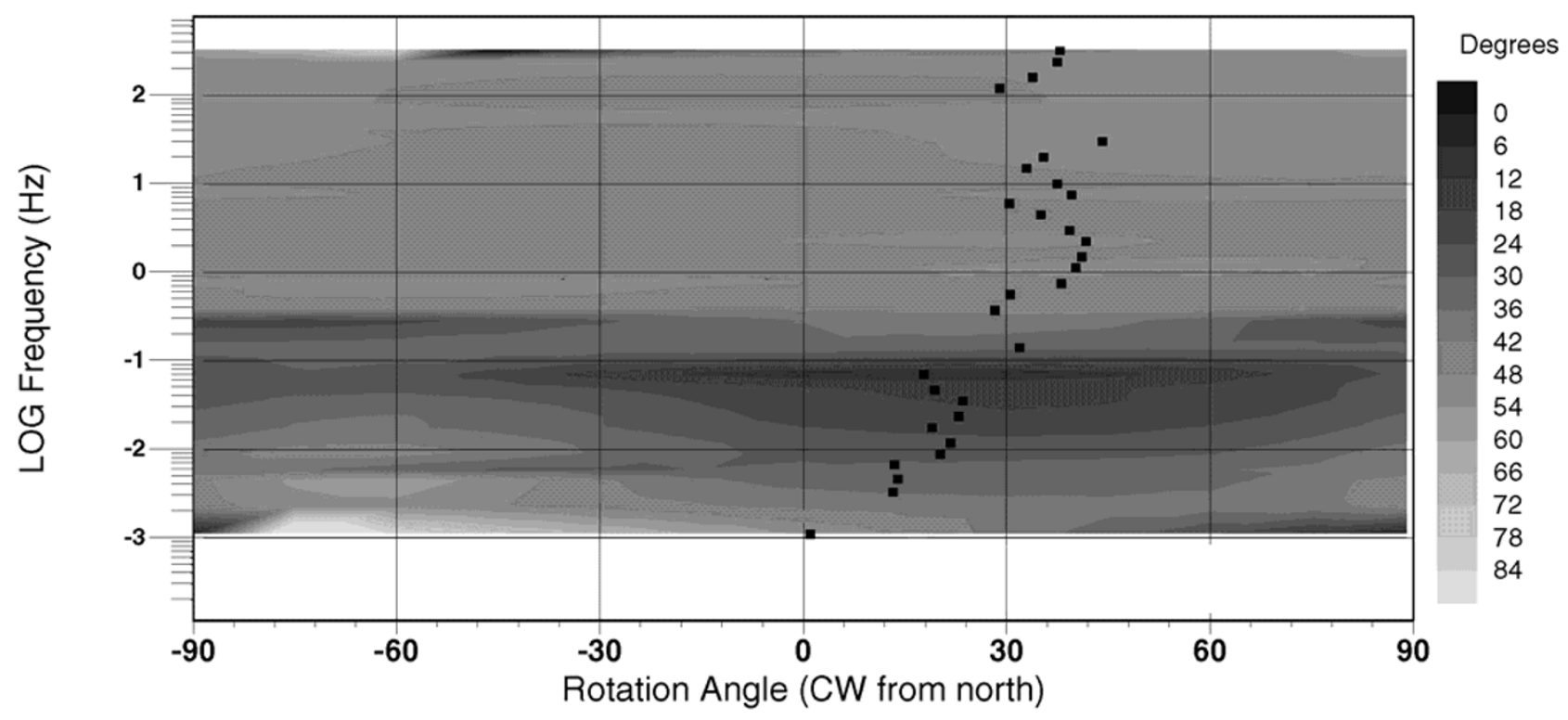

- GB strike angle

Fig. 4. Frequency variation of the apparent resistivities and phases for different Swift rotation angles observed at the station 17. The solid squares are the Groom Bailey rotation angles.

Most of the geological and tectonic features in the study area are aligned along the NW-SE direction (Fig. 2). Based on this observation, the geoelectric strike direction was assumed to be $\mathrm{N} 50^{\circ} \mathrm{W}$ and the apparent resistivities and phases along this direction were assumed to be the TE mode values and those perpendicular, the TM mode values. The tensor decomposition procedure was repeated with the strike angles at the individual stations fixed along the assumed regional strike angle.

The apparent resistivity and phase pseudo-sections in the TE and TM mode are shown in Figs. 5(a) and (b) respectively. Also shown here are the responses of the two-dimensional model to be discussed later. Some static shift is evident from the observed vertical elongations of the appar- ent resistivity contours at stations between 5 and 8 which are not reflected in the phase pseudo-sections.

\section{Static Shifts Considerations and the Two-Di- mensional Modeling}

The static shifts in the apparent resistivities result from the presence of resistivity inhomogeneities in the shallow surface. Due to the random distribution of such inhomogeneities, it is not possible to either detect or estimate the static shifts using the theoretical treatment. Normally some empirical considerations are used for correcting the static shifts, depending upon the nature of the problem at hand. One of the methods is the key layer or the key parameter approach, proposed by Jones (1988). Here the available in- 
formation from other geophysical methods such as the borehole resistivity logs or the seismic studies is used to suitably correct the static shift in the apparent resistivity curves. Another method is based on the assumption that the deep resistivity contrasts lead to smooth variations in the spatial dependence of the apparent resistivities (Jones and Dumas, 1993). Thus the spatial variations of the apparent resistivities are filtered to remove the short wavelength features and the apparent resistivities in the TE mode at low frequency end are shifted so as to correspond to the smoothed values. The TM mode values are then tied to the respective TE mode curves at the high frequency end.

As mentioned earlier, only one borewell (JA2) in the Siwalik region has reached the basement depth of $5027 \mathrm{~m}$. At the Jwalamukhi borewells (JW1 and JW2), the basement could not be reached even at depths of $6720 \mathrm{~m}$. These observations as well as the seismic studies (Raiverman et al., $1983,1994)$ indicate an undulating basement below the sedimentary column in the survey region. Thus the key layer approach may not be suitable for the correction of the static shifts. The compressional tectonics undergone by this region as is evident from the several thrusts, synclines and anticlines, some of which may be deep seated, do not permit the assumption of uniform resistivities at deeper levels. The phase pseudo-sections (Fig. 5(b)) also show some lateral phase variations at low frequencies. In view of these observations, it may not be reasonable to use the method of Jones and Dumas (1993) for the correction of static shifts. The phase of the impedance is not affected by the near surface inhomogeneities (Jones, 1992) and at the same time most of the information on the sub-structure is also available in the phase data. However, information on the resistivity levels is not available in the phase data.

In view of the foregoing discussion, we decided to obtain the geoelectric structure using the apparent resistivities and impedance phases in the TE and TM modes obtained from the GB decomposition as described earlier. In order to accommodate the possibility of the static shifts, the standard errors in the input values of the apparent resistivities were increased by a factor of 100 before inverting the data in the entire data set, so as to decrease their weight in the inversion process. It seems reasonable to assume that by decreasing the weight of the apparent resistivity values the phase of impedance will have a stronger influence on the resistivity structure. At the same time, the true resistivities will be constrained by the weak influence of the apparent resistivity values. Since the phase does not contain any information on the true resistivities, the weak constraints laid by the down-weighed apparent resistivities should be sufficient for constraining the true resistivity values. A uniform half space with a resistivity of $50 \Omega-m$ was used as the starting model for the two-dimensional inversion scheme (Rodi and Mackie, 2001). The smoothing parameter $(\tau)$ for the inversion scheme was set at 5 and the resulting RMS misfit after 30 iterations was 1.2. The observed and modeled pseudo-sections of the apparent resistivities and phases are shown in Figs. 5(a) and (b) respectively. A comparison of the observed and modeled apparent resistivities indicates some static shifts between stations 5 and 8 . However the resistivity levels at other stations show an acceptable corre- spondence between the observed and modeled values.

The geoelectric structure in the top $15 \mathrm{~km}$ block is shown in Fig. 6. The positions of the tectonic elements delineated from the MT studies and topography along the profile are shown on the top part of this figure. The deep resistivity structure is shown in Fig. 7 (vertical exaggeration 1:1) along with the Bouguer gravity variations over the MT profile.

\section{Shallow Crustal Structure}

The geoelectric cross section (Figs. 6 and 7) is indicative of the intense thrusting and folding of the crust in the Siwalik region, with the thickness of the sedimentary layer varying between 3.5 and $8 \mathrm{~km}$. The interpretation of the thrusts and folds derived from the MT studies is shown in Fig. 8(a). For the purpose of comparison, the tectonic elements and the thickness of the Siwalik and Dharamsala sediments in the shallow crust obtained from the gravity and seismic studies (Raiverman et al., 1994) are shown in Fig. 8(b).

The Main boundary thrust is delineated at stations 1 and 3. Data could not be collected on the NE of station 1 because of two reasons, firstly, there were no suitable stations available here for MT data collection and secondly the roads here run along the known geological and tectonic features over a distance of more than $50 \mathrm{~km}$. Only the top of the NE dipping MBT is seen at shallow depths between stations 1 and 3. On the SW, the Palampur thrust (PT) is delineated at station 7. The resistivity distribution between the MBT and PT is complex, which may be the result of the post sedimentation tectonic movements along the MBT and PT. Some indications of SW dipping structures between the stations 1 and 3 are observed in the geoelectric cross section. However not much significance is attached to this fact because the uninterpreted seismic data (Raiverman et al., 1994) show predominantly NE dipping reflections in this region. On the SW of PT, about $60 \mathrm{~km}$ long fold belt, consisting of the Sarkaghat anticline (stations 7-11), Lambagraon syncline (stations 10-13) and the Bahl anticline (stations 13-17) runs along the entire profile. The Siwalik sediments are delineated on the SW of this anticline. The resistive structure at shallow depths beneath the Sarkaghat region (stations 9 and 10) indicates the possibility of an additional thrust located along the NE shoulder of the anticline. The position of this thrust is shown in Fig. 8(a) by the dashed line. The gravity studies indicate a thrust zone branching to the NW from PT on the south of stations 8 and 9 (Fig. 2). It may be inferred from these observations that PT is composed of two thrust zones, at least below the MT profile and on its immediate SW which merge together at a distance of about $30 \mathrm{~km}$ to the south of MT survey profile. Lambagraon syncline separates the Sarkaghat anticline from the Bahl anticline on the SW. Based on the seismic and gravity studies the Gambhar thrust (between stations 13 and 15) and Barsar counter-thrust (between stations 15 and 16) are reported by Raiverman et al. (1994) and Karunakaran and Ranga Rao (1976). The signatures of the Barsar counter-thrust and the Gambhar thrust were however not evident in the geoelectric cross section. Some indications of high resistivity are observed beneath station 15 . It is not clear whether this represents the Gambhar thrust or the upward extension of the Bahl anticline. A SW dipping counter-thrust is delineated in the present studies beneath the 


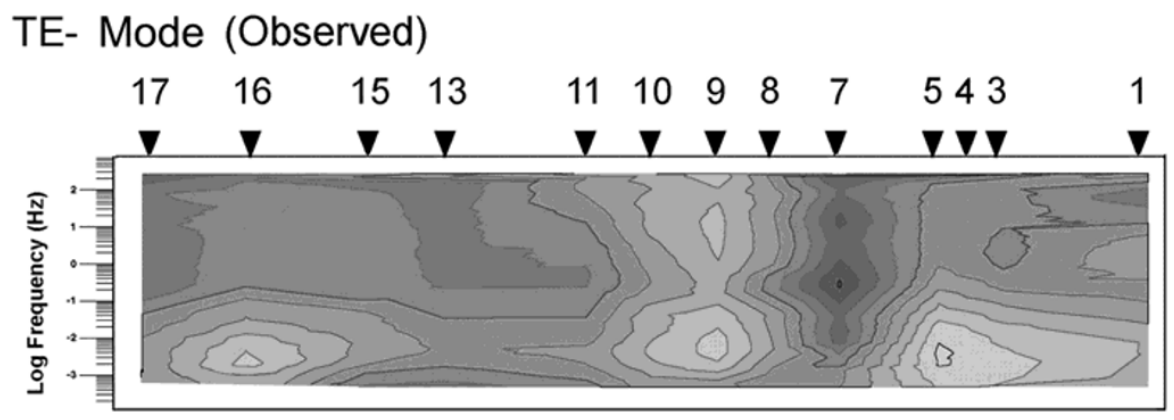

TE- Mode (Model)

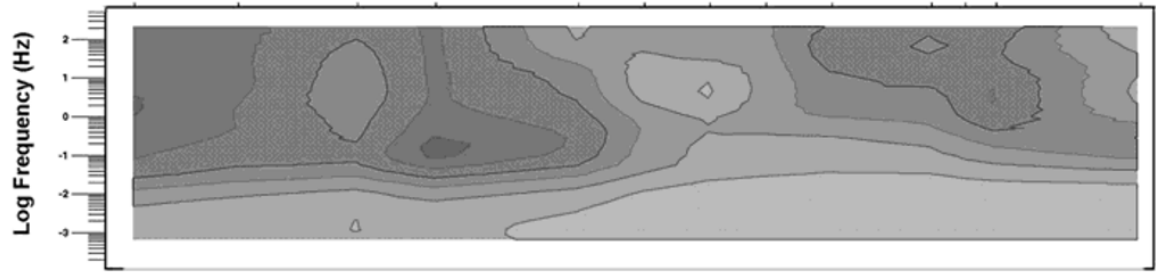

TM- Mode (Observed)

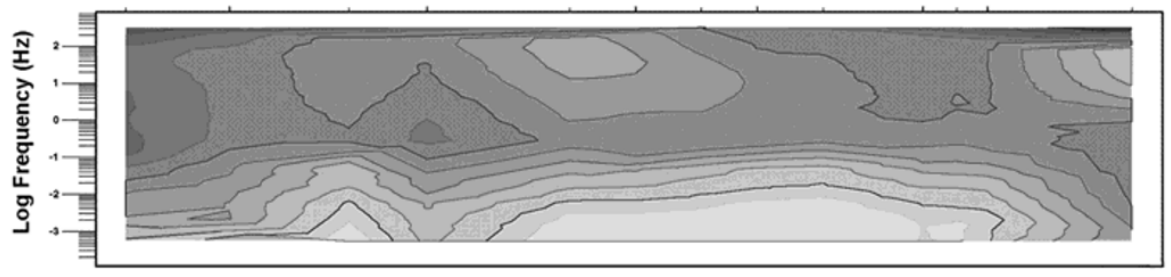

TM- Mode (Model)

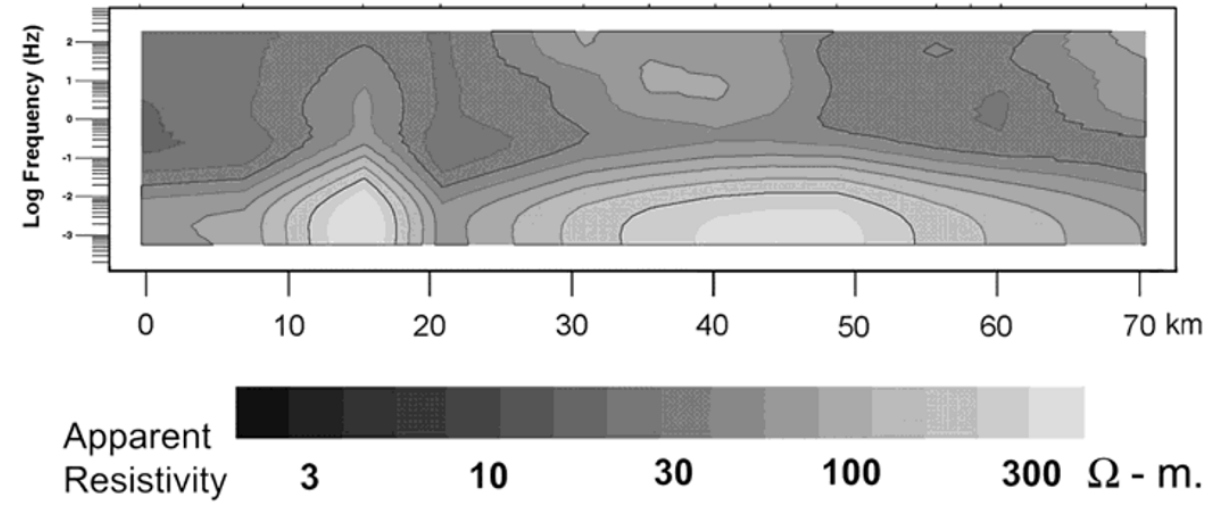

Fig. 5(a). Apparent resistivity pseudo-sections in the TE and TM mode. Forward responses of the model shown in Fig. 7 are also shown for the sake of comparison. The static shifts are noticed at the stations between 5 and 8 in the observed apparent resistivities.

station 16 , extending to the depth of about $4 \mathrm{~km}$. The gravity studies show about $50 \mathrm{~km}$ long counter-thrust at station 16 (Fig. 2). The geological studies (Fig. 1) do indicate the exposed Middle and Lower Siwalik sequences to the south of station 16, indicating the possibility of a thrust zone.

The undulations in the basement topography observed in the MT studies are in good qualitative correspondence with the short wavelength features in the Bouguer gravity (Fig. 7) with gravity highs of about $20 \mathrm{mGal}$ over the Sarkaghat and Bahl anticlines and gravity lows over the Lambagraon syncline and on the SW end of the profile, where the basement depth increases to about $15 \mathrm{~km}$. The long wavelength decrease towards the NE is a part of the regional decrease in the gravity field towards the NE and is a result of the deepening of the subducting Indian crust towards the Himalayan collision region.

The broad similarity of the tectonic features delineated from the MT and seismic studies is evident from Fig. 8(a) and (b). However their relative positions and the lateral and depth extents are different because the seismic and MT profiles are not coincident. Thus in the seismic section, the Lambagraon syncline is delineated as a wide and shallow sedimentary basin with width and depth of 20 and $8 \mathrm{~km}$ respectively. The corresponding values of 10 and $12 \mathrm{~km}$ respectively from the MT studies show that this syncline may be deeper and narrow syncline. Moreover the seismic 


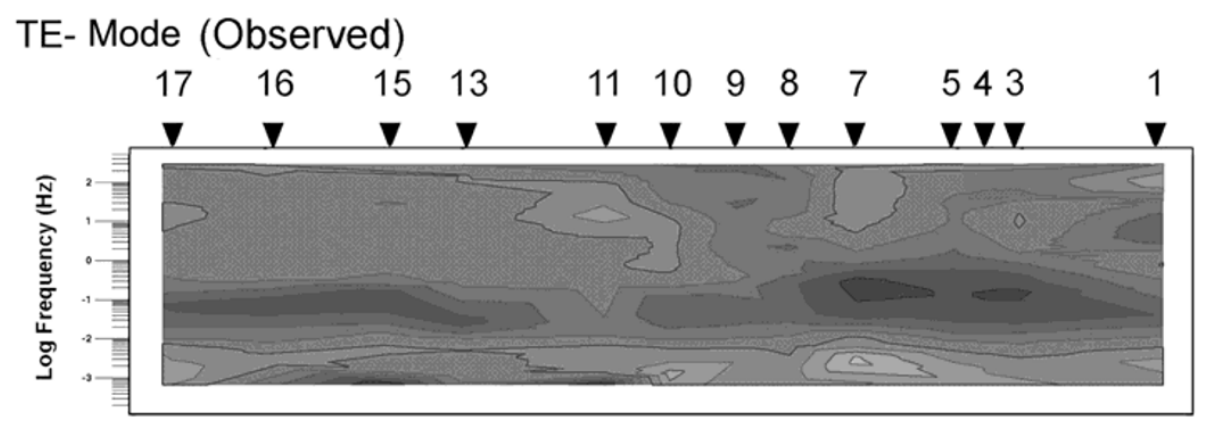

TE- Mode (Model)

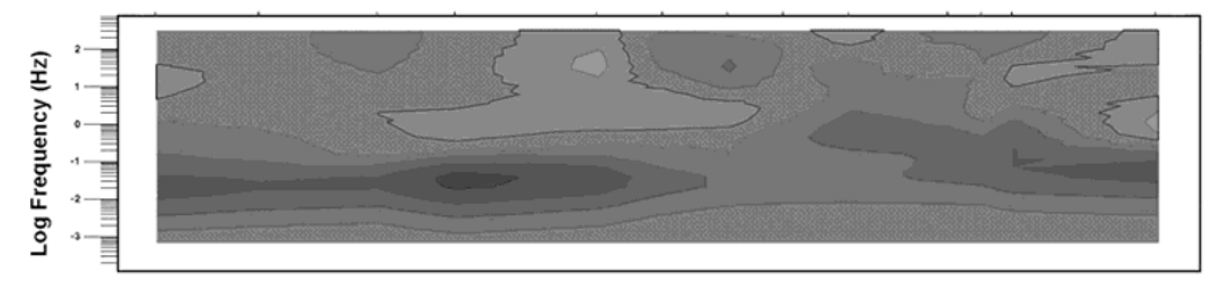

TM- Mode (Observed)

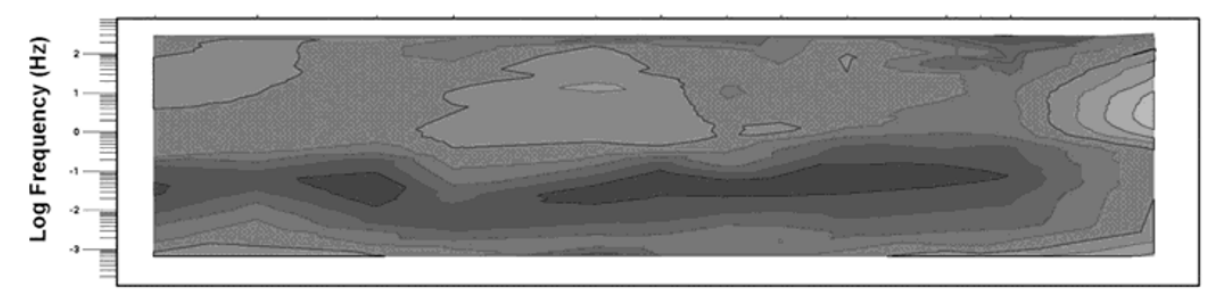

TM- Mode (Model)

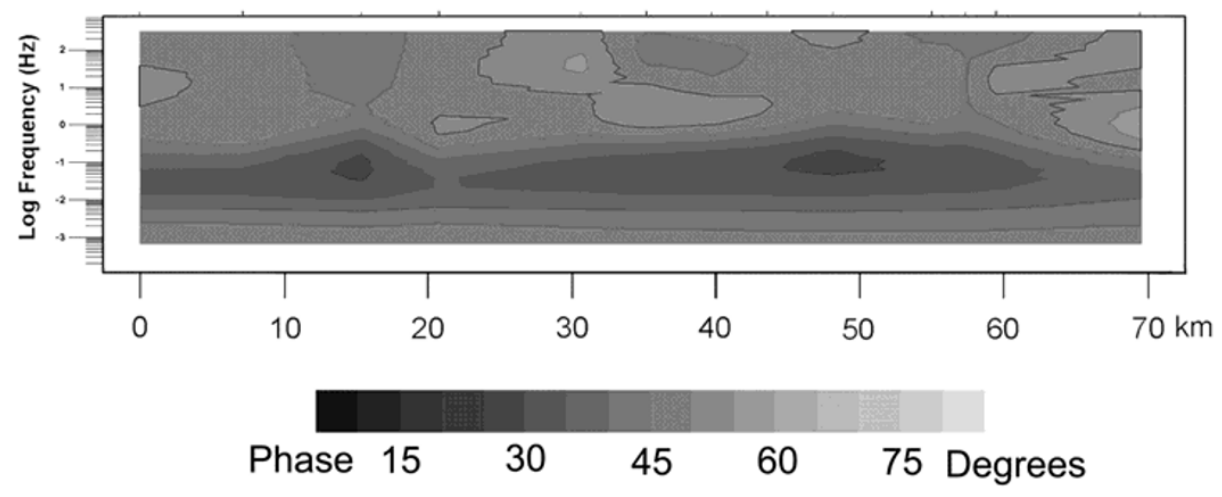

Fig. 5(b). Phase pseudo-sections in the TE and TM mode. Forward responses of the model shown in Fig. 7 are also shown for the sake of comparison.

profile covers the Paror anticline (Fig. 2) whereas the MT profile passes through the Sarkaghat anticline.

\section{Discussion on the Deep Crust}

A resistive crust with a resistivity of more than 1000 $\Omega-m$ was delineated beneath the Siwalik sequences. The crust is underlain by a conductive layer with a resistivity of about $100 \Omega-m$. This conductive layer is delineated at depth of about $35-50 \mathrm{~km}$ throughout the profile and becomes shallow (about $35 \mathrm{~km}$ deep) underneath the Bahl anticline and Lambagraon syncline and also on the NE part of the profile towards the MBT. The depth to this conductor increases to about $50 \mathrm{~km}$ below the Sarkaghat anticline and Palampur thrust. The GDS studies (Reddy and Arora, 1993) have delineated this conductor at shallower depth $(15 \mathrm{~km})$ which is not in agreement with observations here. Since the top of the conductive layer is a strongly constrained parameter in MT responses, the conductive layer is assumed to be at depth of $35-50 \mathrm{~km}$.

As mentioned earlier, while discussing the regional strike directions, the electromagnetic responses at the stations 16 and 17 were influenced by a conductive body on the south of the profile. This body has a sufficiently strong influence on the strike angles at low frequency at these stations. Its effect on the final geoelectric structure however cannot be estimated unless a three-dimensional interpretation is performed. It may however be assumed here that in the absence of this conductive body, the resistivity and depth to the deep crustal conductive layer below the crust would have been higher by unknown amount. Thus the crustal thick- 

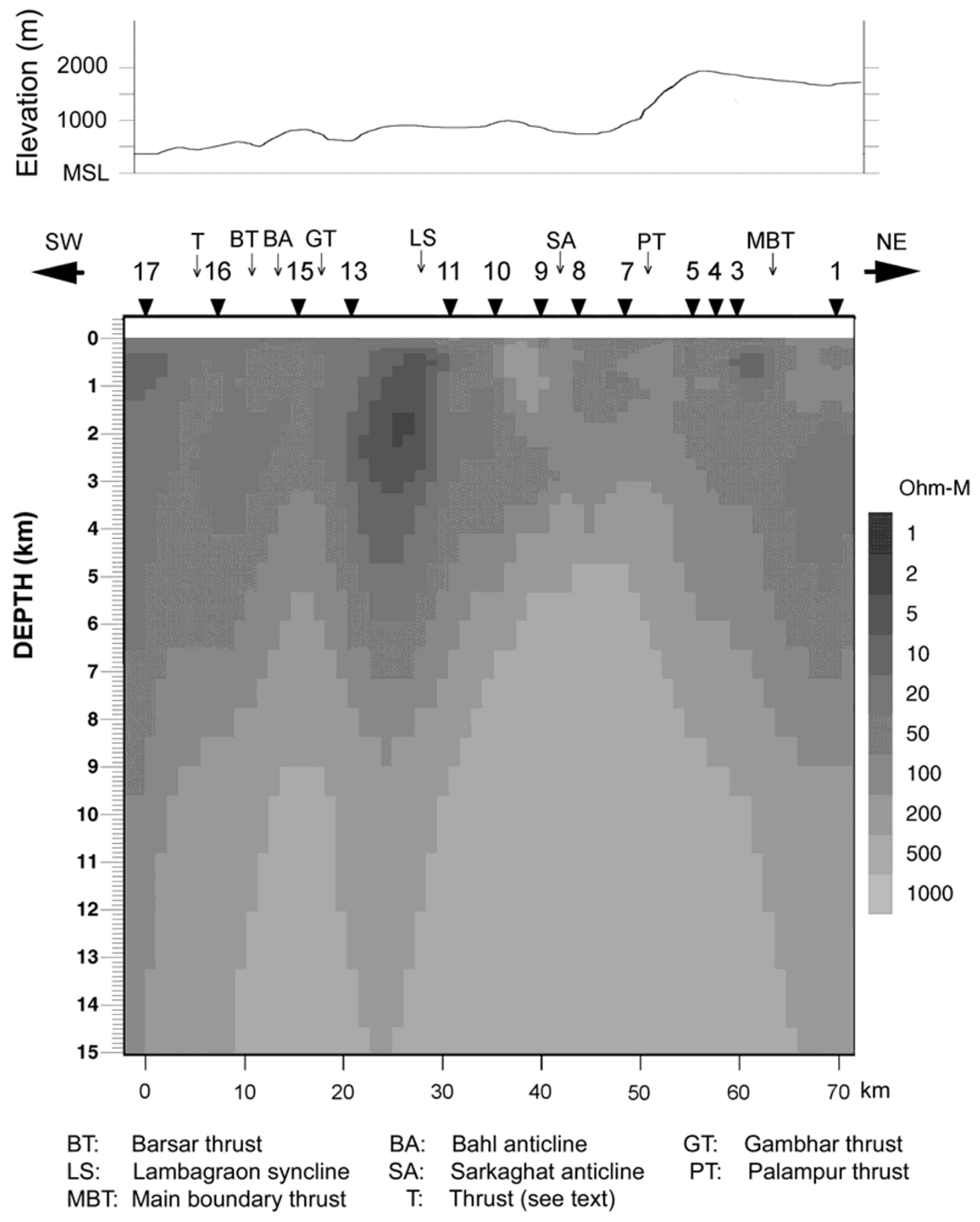

Fig. 6. Shallow geoelectric structure (in the top $15 \mathrm{~km}$ ). The location of the tectonic elements are marked on the top part of the figure. Topography along the MT profile is also shown at the top.

ness at these stations may be underestimated in this study. The shallow crustal structure at these stations however may not be influenced to any appreciable extent by this conductive body, as is evident from the reasonable agreement of the high frequency strike angles $(>0.1 \mathrm{~Hz})$ with the regional strike direction.

Studies over subducting plates in several parts of the world have revealed similar high conductivity layers in the deep crust (Jones, 1992; Ádám, 1980). Attempts have been made to explain these deep crustal conductivities on the basis of the fluids in open pores, partial melting of the deep crustal rocks, possible serpentinization in the remnants of the oceanic crusts and grain boundary graphite films. The geothermal studies over various parts of the Siwalik region indicate a high heat-flow of about $100 \mathrm{mWm}^{-2}$ (Ravi Shanker, 1988). Thus the high conductivity below the Siwalik crust seems to be due to partial melting of the deep crustal rocks.

\section{Conclusions}

The wide band MT studies at 17 stations in the Lesser Himalayas between the main boundary thrust and the main 

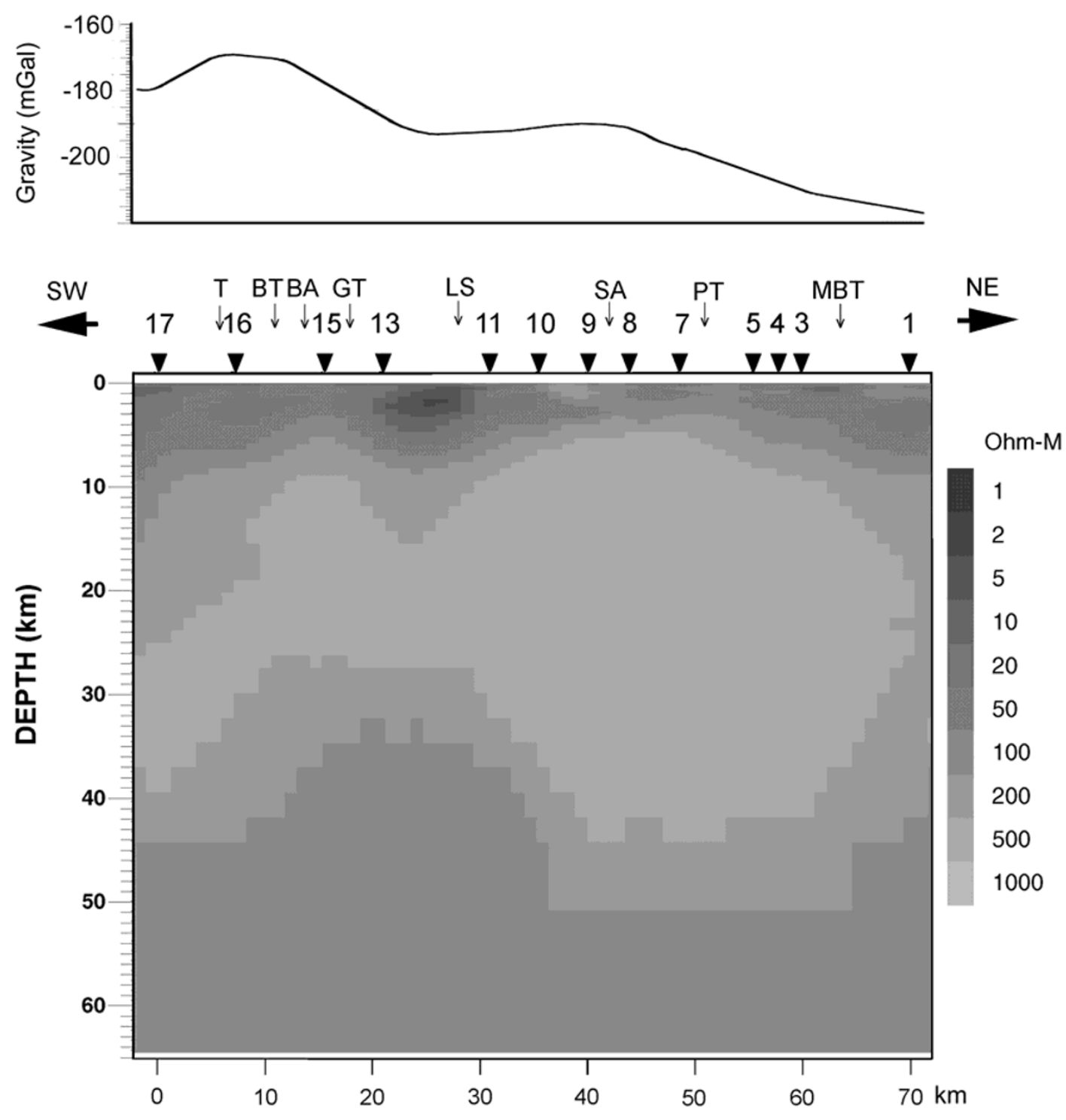

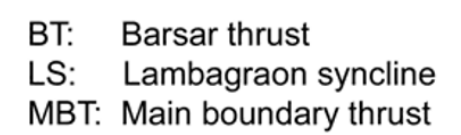

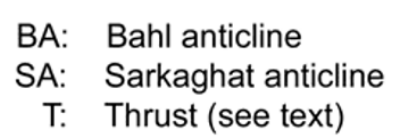

\section{GT: Gambhar thrust \\ PT: Palampur thrust}

Fig. 7. Deep crustal resistivity section (vertical exaggeration 1:1) obtained from two-dimensional inversion along with the Bouguer gravity variations along the MT profile. The positions of the tectonic elements are marked on the top part of the figure.

frontal thrust have delineated sediments with thickness varying from 3.5 to about $8 \mathrm{~km}$ deposited on the basement with resistivity of about $1000 \Omega-m$. The thickness of the individual sedimentary sequences however could not be delineated, presumably because of the overlapping nature of their electrical resistivities. A conductive layer with a resistivity of about $100 \Omega-m$ was delineated beneath the Siwalik crust. This layer is located at a shallow depth of about $35 \mathrm{~km}$ below the Lambagraon syncline and the Bahl anticline and also towards the main boundary thrust on the NE whereas, below the Sarkaghat anticline and Palampur thrust as well as on the SW, the depth to this conductive layer is about 50 $\mathrm{km}$. Studies on the depth of the earthquake focii in this region (Ni and Barazangi, 1984) indicate that the top of the subducting Indian plate is about $10 \mathrm{~km}$ beneath the Siwa- lik region. Thus the conductive layer seems to be located in the deep crust of the subducting Indian plate. It may be inferred from these studies that the thrusts and counter-thrusts in the Siwalik region are shallow features resulting from the thin skin tectonics whereas, the deep crustal level tectonics may have had significant contribution to the formation of the synclines and anticlines.

Acknowledgments. This work is a part of the project HIMPROBE (ES/16/094/97), funded by the Department of Science and Technology, Govt of India, New Delhi. We are grateful to Prof. B. P. Singh, (Retired) Director, Indian institute of Geomagnetism, Mumbai for his constant encouragement and support during the course of this work. Our sincere thanks to Mr. C. Selvaraj, for his enthusiastic participation in the field work and the instrumentation support. The authors were immensely benefited by the useful sug- 


\section{A. Interpreted MT section}

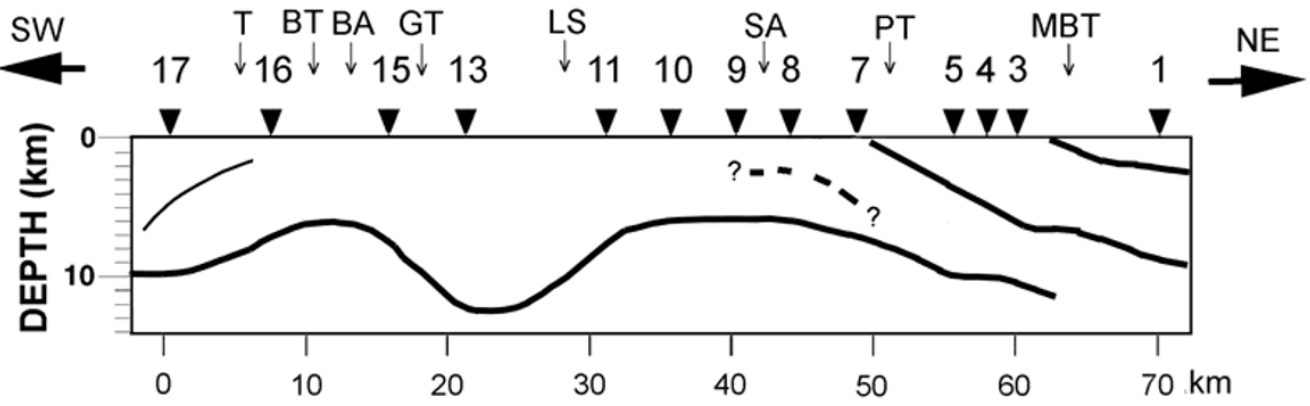

\section{B. Seismic section}

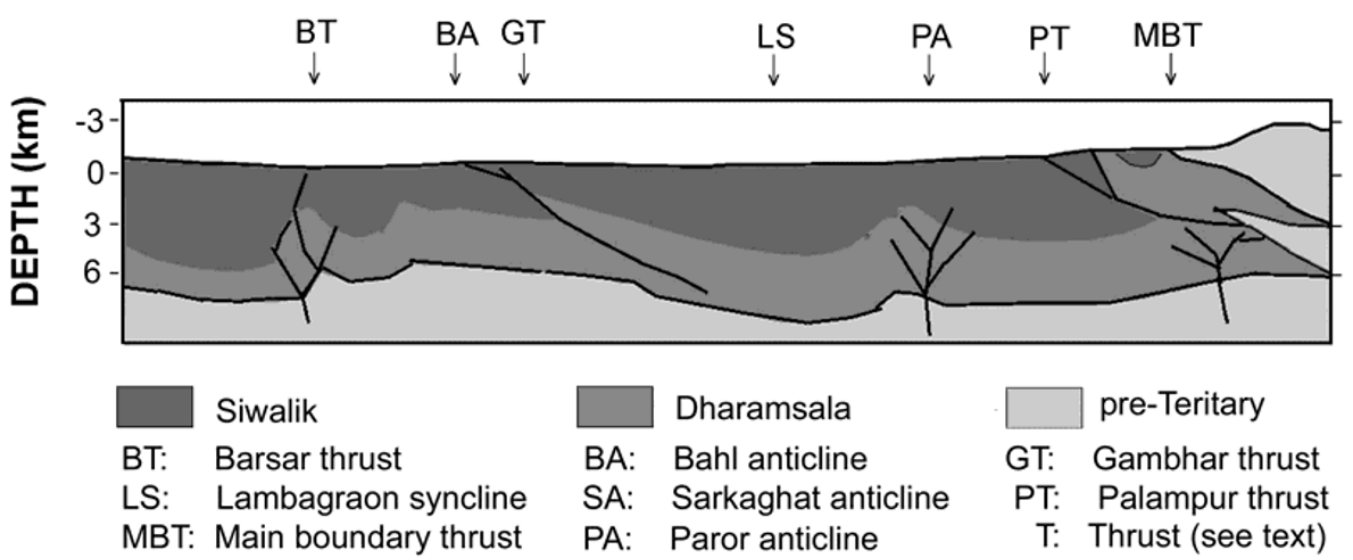

Fig. 8. Tectonic interpretation of the Siwalik region (a) based on the MT results (Fig. 7) and (b) seismic studies of Raiverman et al. (1994). The major tectonic elements are marked on the top part of the diagrams. The dashed line (?..... ?) denotes a thrust branching out from PT (see text).

gestions and comments of Shri T. S. Balakrishnan, (Retired) Director of Geophysics, Bombay offshore project, Oil and Natural Gas Commission, India. The authors express their gratitude to Dr. G. Marquis and the anonymous referee for their constructive and critical comments and valuable suggestions, which helped us improve the quality of the paper remarkably.

\section{References}

Ádám, A., The change of electrical structure between an orogenic and an ancient tectonic area, J. Geomag. Geoelectr., 32, 1-46, 1980.

Biswas, S. K., Status of exploration for Hydrocarbons in Siwalik basins of India and future trends, Himalayan Geology, 15, 283-300, 1994.

DST Expert group, Report of the expert group on the NW Himalayan geotransect programme (NWHGP), Earth system Science division, Department of Science and Technology, Govt of India, 1995 (unpublished)

Gansser, A., Geology of the Himalayas, 289 pp., Interscience Publ., New York, 1964.

Groom, R. W. and R. C. Bailey, Decomposition of the magnetotelluric impedance tensor in the presence of local three dimensional galvanic distortions, J. Geophys. Res., 94, 1913-1925, 1989.

Jones, A. G., Static shift of magnetotelluric data and its removal in a sedimentary basin environment, Geophysics, 51(7), 967-978, 1988.

Jones, A. G., Electrical conductivity of the continental lower crust, in Developments in Geotectonics, 23, Continental Lower Crust, edited by D. M. Fountain, R. Arculus, and R. W. Kay, pp. 87-143, Elsevier Science Publishers, Amsterdam, 1992.

Jones, A. G. and I. Dumas, Electromagnetic Image of a volcanic zone, Phys. Earth Planet. Inter., 81, 289-314, 1993.

Karunakaran, C. and A. Ranga Rao, Status of exploration for hydrocarbons in the Himalayan region-Contributions to stratigraphy and structure, Geol. Surv. India Misc. Publ., No:41, 1-66, 1976.
Mahadevan, T. M., Deep Continental structure of India: A review, Geol. Soc. India, Memoir No: 28, 348, 1994.

Ni, J. and M. Barazangi, Seismotectonics of the Himalayan collision zone: Geometry of the underthrusting Indian plate beneath the Himalaya, $J$ Geophys. Res., 89(B2), 1147-1163, 1984.

Pilgrim, A., Correlation of the Siwaliks with mammal horizons of Europe, Rec. Geol. Surv. India, 43, 1-264, 1913.

Raiverman, V., S. V. Kunte, and A. Mukerjea, Basin geometry, Cenozoic sedimentation and hydrocarbon prospects in north western Himalaya and Indo-Gangetic plains, Petroleum Asia Journal: Petroliferous basins of India, VI(4), 67-92, 1983.

Raiverman, V., A. K. Srivastava, and D. N. Prasad, Structural style in the northwestern Himalayan foothills, in Himalayan Geology, Siwalik Foreland Basin of Himalaya, edited by R. Kumar, S. K. Ghosh, and N. R. Phadtare, 15, 263-280, Oxford \& IBH publishing Co. Pvt. Ltd. New Delhi, 1994.

Ravi Shanker, Heat-flow map of India and discussions on its geological and economic significance, Indian Minerals, 42, 89-110, 1988.

Reddy, C. D. and B. R. Arora, Quantitative interpretation of geomagnetic induction response across the thrust zones of Himalaya along the Ganga Yamuna valley, J. Geomag. Geoelectr., 45, 775-785, 1993.

Rodi, W. and R. L. Mackie, Nonlinear conjugate gradients algorithm for 2D magnetotelluric inversions, Geophysics, 66, 174-187, 2001.

Vozoff, K., The magnetotelluric method in the exploration of sedimentary basins, Geophysics, 37, 98-141, 1972.

Wight, D. E. and F. X. Bostick, Cascade decimation A technique for real time estimation of power spectra, Proc. IEEE Intern. Conf. Accoustic, Speech Signal Processing, Denver, Colorado, April, 9-11, pp. 626-629, 1980

S. G. Gokarn (e-mail: gokarn@iig.iigm.res.in), C. K. Rao, and G. Gupta 